\title{
Neurally adjusted ventilatory assist and proportional assist ventilation both improve patient-ventilator interaction
}

\author{
Matthieu Schmidt ${ }^{1,2,3,6^{*}}$, Felix Kindler ${ }^{3}$, Jérôme Cecchini ${ }^{1,2}$, Tymothée Poitou ${ }^{4}$, Elise Morawiec ${ }^{1,2,3}$, \\ Romain Persichini ${ }^{3}$, Thomas Similowski ${ }^{1,2,3}$ and Alexandre Demoule ${ }^{1,2,3,5}$
}

\begin{abstract}
Introduction: The objective was to compare the impact of three assistance levels of different modes of mechanical ventilation; neurally adjusted ventilatory assist (NAVA), proportional assist ventilation (PAV), and pressure support ventilation (PSV) on major features of patient-ventilator interaction.

Methods: PSV, NAVA, and PAV were set to obtain a tidal volume $\left(\mathrm{V}_{T}\right)$ of 6 to $8 \mathrm{ml} / \mathrm{kg}\left(\mathrm{PSV}_{100}, \mathrm{NAVA}_{100}\right.$, and PAV $\left.{ }_{100}\right)$ in 16 intubated patients. Assistance was further decreased by 50\% (PSV $V_{50}, N A V A_{50}$, and $\left.P A V_{50}\right)$ and then increased by $50 \%\left(\mathrm{PSV}_{150}, \mathrm{NAVA}_{150}\right.$, and $\mathrm{PAV}_{150}$ ) with all modes. The three modes were randomly applied. Airway flow and pressure, electrical activity of the diaphragm (EAdi), and blood gases were measured. $V_{T}$, peak EAdi, coefficient of variation of $V_{T}$ and $E A d i$, and the prevalence of the main patient-ventilator asynchronies were calculated.
\end{abstract}

Results: PAV and NAVA prevented the increase of $\mathrm{V}_{T}$ with high levels of assistance (median 7.4 (interquartile range (IQR) 5.7 to 10.1$) \mathrm{ml} / \mathrm{kg}$ and 7.4 (IQR, 5.9 to 10.5$) \mathrm{ml} / \mathrm{kg}$ with $\mathrm{PAV}_{150}$ and $\mathrm{NAVA}_{150}$ versus 10.9 (IQR, 8.9 to 12.0$) \mathrm{ml} / \mathrm{kg}$ with PSV $\left.{ }_{150}, P<0.05\right)$. EAdi was higher with PAV than with PSV at level 100 and level ${ }_{150}$. The coefficient of variation of $V_{T}$ was higher with NAVA and PAV (19 (IQR, 14 to 31)\% and 21 (IQR 16 to 29)\% with NAVA 100 and PAV 100 versus 13 (IQR 11 to 18)\% with PSV ${ }_{100}, P<0.05$ ). The prevalence of ineffective triggering was lower with PAV and NAVA than with PSV $(P<0.05)$, but the prevalence of double triggering was higher with NAVA than with PAV and PSV $(P<0.05)$.

Conclusions: PAV and NAVA both prevent overdistention, improve neuromechanical coupling, restore the variability of the breathing pattern, and decrease patient-ventilator asynchrony in fairly similar ways compared with PSV. Further studies are needed to evaluate the possible clinical benefits of NAVA and PAV on clinical outcomes.

Trial registration: Clinicaltrials.gov NCT02056093. Registered 18 December 2013.

\section{Introduction}

Partial ventilatory assistance minimizes adverse effects of controlled mechanical ventilation, such as excessive sedation and ventilator-induced diaphragm dysfunction [1-3]. The most widely used partial ventilatory assistance mode is pressure support ventilation (PSV) [4], in which a constant preset level of pressure assists each inspiration, regardless of the patient's inspiratory effort. Mismatching between patient demand and level of assistance is therefore

\footnotetext{
* Correspondence: matthieuschmidt@yahoo.fr

'Sorbonne Universités, UPMC Univ Paris 06, UMR_S 1158 Neurophysiologie

Respiratoire Expérimentale et Clinique, F-75005 Paris, France

${ }^{2}$ INSERM, UMR_S 1158 Neurophysiologie Respiratoire Expérimentale et

Clinique, F-75005 Paris, France

Full list of author information is available at the end of the article
}

possible and can be potentially harmful: underassistance may induce respiratory discomfort [5], and overassistance may cause lung overdistention and volutrauma [6]. Of note, underassistance and overassistance may both generate patient-ventilator asynchrony that is associated with poorer clinical outcomes [7].

Proportional Assisted Ventilation (PAV) and Neurally Adjusted Ventilatory Assist (NAVA) have been designed to overcome this weakness of PSV. These two modes adjust proportionally the amount of assistance delivered. NAVA adjusts ventilator assistance to the electrical activity of the diaphragm (EAdi), recorded with an esophageal catheter [8]. PAV adjusts ventilator assistance to the activity of respiratory muscles estimated by an 
algorithm [9]. Previous studies have shown the potential benefits of PAV and NAVA to prevent the risk of overassistance [10-13], to increase the variability of the breathing pattern [14-20], and to improve patient-ventilator interaction and synchrony [11,12,21-26]. PAV and NAVA have been previously compared with PSV but not with each other. This comparison would be clinically relevant, as these two modes have their own specific strengths and weaknesses $[9,27]$.

In the study reported here, we hypothesized that PAV and NAVA improve patient-ventilator interaction in similar ways. The aim of this study was therefore to compare, in patients recovering from acute respiratory failure, the respective impacts of various levels of NAVA, PAV, and PSV on four major features of patient-ventilator interaction: (1) breathing pattern, including prevention of overassistance; (2) respiratory drive; (3) breathing pattern variability, and (4) patient-ventilator synchrony.

\section{Materials and methods}

The study was conducted over a period of 3 months in a 10-bed Intensive Care Unit (ICU) in an 1,800-bed university hospital. The protocol was approved by the Comite de Protection des Personnes Ile de France VI. Informed consent was obtained from patients or relatives.

\section{Patients}

Patients initially intubated and ventilated in the ICU were eligible for inclusion in the study if (1) they had been ventilated for acute respiratory failure via an endotracheal tube for more than 48 hours, (2) the condition that had required mechanical ventilation had improved (in particular, the ability to trigger the ventilator with an $\mathrm{FiO}_{2}$ of $\leq 50 \%$ and positive end-expiratory pressure (PEEP) $\leq 5 \mathrm{cmH}_{2} \mathrm{O}$ ), (3) sedation had been stopped for more than 6 hours, (4) hemodynamic stability was achieved without vasopressor or inotropic medication. Exclusion criteria were known or suspected phrenic nerve dysfunction or other neuromuscular disorders that may involve the diaphragm or impair respiratory drive. Patients with contraindications to EAdi catheter placement (for example, gastroesophageal varices or obstruction, recent gastroesophageal surgery, facial surgery or trauma, or upper gastrointestinal bleeding) were excluded. Patients in whom the decision had been made to withhold life-sustaining treatment were also ineligible for inclusion.

\section{Ventilation equipment}

The conventional nasogastric tube was removed and replaced by a 16 Fr EAdi catheter (Maquet Critical Care, Solna, Sweden), and its position was controlled according to the manufacturer's recommendations [28]. PSV and NAVA were delivered by using a Servo-I ventilator
(Maquet Critical Care), and PAV+ was delivered by using a PB840 ventilator (Covidien, Boulder, CO, USA). Male and female patients were ventilated with an 8- and 7.5-mm internal diameter endotracheal tube, respectively.

\section{Study protocol}

Inspiratory pressure support level was initially titrated to obtain a tidal volume $\left(\mathrm{V}_{\mathrm{T}}\right)$ of 6 to $8 \mathrm{ml} / \mathrm{kg}$ of predicted ideal body weight. Flow-trigger sensitivity was set at the lowest possible level without inducing autotriggering, and cycling-off was set at 30\% of peak inspiratory flow (default value). This level of assistance was defined as PSV $_{100}$. Patients were then switched to NAVA, and the corresponding NAVA level to obtain a similar $\mathrm{V}_{\mathrm{T}}$ of 6 to $8 \mathrm{ml} / \mathrm{kg}$ was determined during a 5 -minute period. This NAVA level was termed $\mathrm{NAVA}_{100}$. Patients were finally switched to PAV, and the percentage unloading (\%Assist) was set also to obtain a similar $V_{T}$ of 6 to $8 \mathrm{ml} / \mathrm{kg}$. This \%Assist corresponded to $\mathrm{PAV}_{100}$. In each of the three modes, the assist level was further decreased by $50 \%$, corresponding to $\mathrm{PSV}_{50}, \mathrm{NAVA}_{50}$, and $\mathrm{PAV}_{50}$ and then increased by $50 \%$, corresponding to $\mathrm{PSV}_{150}$, $\mathrm{NAVA}_{150}$, and $\mathrm{PAV}_{150}$. In the Results section, $\mathrm{PSV}_{100}$, $\mathrm{NAVA}_{100}$, and $\mathrm{PAV}_{100}$ define a medium assistance level also termed level ${ }_{100} ; \mathrm{PSV}_{50}, \mathrm{NAVA}_{50}$, and $\mathrm{PAV}_{50}$ define a low assistance level, also termed level ${ }_{50}$; and $\mathrm{PSV}_{150}$, $\mathrm{NAVA}_{150}$, and $\mathrm{PAV} \mathrm{V}_{150}$ define a high assistance level also termed level ${ }_{150}$. Of note, inspiratory pressure-support level in $\mathrm{PSV}_{50}$ could not be lower than $7 \mathrm{cmH}_{2} \mathrm{O}$. A high upper pressure limit at $45 \mathrm{cmH}_{2} \mathrm{O}$ was set in PAV and NAVA.

Positive end-expiratory pressure (PEEP) and inspired oxygen fraction $\left(\mathrm{FiO}_{2}\right)$ were maintained constant throughout the study period at the values in use before patient enrollment. The endotracheal tube was suctioned before the beginning of each trial. Each patient underwent three 30-minute trials, in each mode, consisting of 20-minute stabilization followed by 10 -minute recording stored on a computer for further analysis. The three modes were applied in computer-generated random order. At the end of each trial, arterial blood was sampled for gas analysis (Radiometer ABL 330, Tacussel, Copenhagen, Denmark) via a catheter, and dyspnea was rated by using a visual analogue scale when possible.

\section{Data acquisition}

Flow was measured with a heated Fleisch pneumotachograph, dead space $51 \mathrm{ml}$ (Hans Rudolph, Kansas City, $\mathrm{MO}$, USA) and airway pressure was measured by a pressure transducer (DP 15-32, Validyne, Northridge, CA, USA) for all modes. Digital EAdi signal was converted into an analog signal (National Instruments, Austin, TX, USA). During all three modes of ventilation, the EAdi waveform was simultaneously recorded with flow and 
airway pressure from the respective ventilator (see Additional file 1). All signals were digitized at a $100-\mathrm{Hz}$ sampling rate (PowerLab/4SP, ADInstruments, Castle Hill, Australia) and recorded on a personal computer for subsequent analysis (Chart software, ADInstruments, Castle Hill, Australia).

\section{Data analysis}

\section{Respiratory Parameters and Breathing Pattern}

Neural respiratory rate $(R R), V_{T}$, duration of pneumatic inspiration $(\mathrm{Ti})$, maximum EAdi, $\left(\mathrm{EAdi}_{\max }\right)$, area under the curve of EAdi during inspiratory time $\left(\mathrm{EAdi}_{\mathrm{AUC}}\right.$, integrated from baseline to peak), and the $\mathrm{V}_{\mathrm{T}^{-}}(\mathrm{ml} / \mathrm{kg}) /$ Eadi $_{\text {max }}$ ratio were calculated offline from the 10-minute airway flow and EAdi recordings. The coefficient of variation (standard deviation divided by the mean) for both flow $\left(\mathrm{CV}_{\mathrm{VT}}\right)$ and EAdi-related variables $\left(\mathrm{CV}_{\text {EAdimax }}\right)$ was calculated. Maximum $\left(\mathrm{P}_{\max }\right)$ and mean inspiratory airway pressure $\left(\mathrm{P}_{\text {mean }}\right)$ were measured and calculated from airway pressure recordings.

\section{Patient-ventilator interaction}

Within the three modes and in all conditions, correlations between EAdi $_{\max }$ and $\mathrm{P}_{\max }$ and between EAdi $_{\mathrm{AUC}}$ and $V_{T}$ were calculated. The inspiratory trigger delay was measured as the time difference between the beginning of the increase in the EAdi signal and the beginning of the ventilator inspiratory flow. The expiratory trigger delay was measured as the time difference between EAdi $_{\max }$ and the end of the insufflation, as defined by a ventilator inspiratory flow equal to zero. Using the EAdi waveform, we quantified the three main types of asynchronies accordingly to previously published definitions [7,25] (see also Additional file 2): (1) ineffective efforts; (2) auto-triggering, and (3) double triggering. Of note, only type II double triggering, defined as one neural inspiration triggering two breath cycles, was considered [25] (see example in Additional file 3). The number of each type of asynchrony was reported as the total number of each event per minute. A global asynchrony index (AI) was computed [7].

\section{Statistical analysis}

Statistical analysis was performed with Prism 4.01 software (GraphPad Software, San Diego, CA, USA). Normality testing failed for all results (KolmogorovSmirnov). Results are therefore expressed as median (25 to 75 interquartile range). Within each of the three assistance level groups (that is, level ${ }_{50}$, level ${ }_{100}$, and level $_{150}$ ), Friedman ANOVA for repeated measures was performed to compare breathing pattern, variability, prevalence of the main asynchronies and blood gases measured with PAV, NAVA, and PSV, respectively. Comparison between the three modes was followed, when appropriate, by a pairwise comparison by using the Dunn post/hoc test. The relationships among both EAdi $\mathrm{imax}_{\max }$ and $\mathrm{P}_{\max }$ and EAdi $\mathrm{AUC}_{\mathrm{AUC}}$ and $\mathrm{V}_{\mathrm{T}}$ were examined by using a linear regression analysis, and the coefficient of correlation $\left(\mathrm{r}^{2}\right)$ was determined. Differences were considered significant when the probability $\mathrm{p}$ of a type I error was less than $5 \%$.

\section{Results}

The study pertains to a convenience sample of 16 patients (10 males). Their main characteristics and the precipitating factor of acute respiratory failure are summarized in Table 1. Respective assistance levels used for each mode are reported in Table 2. Of note, three patients had chronic obstructive pulmonary disease (COPD) (patients 5, 7, and 16).

Breathing pattern and electrical activity of the diaphragm Group median values for representative breathing pattern variables are provided in Figure 1 and Figure 2 (see also Additional file 4). Inspiratory pressures for each patient under all conditions are displayed in Additional file 4. Median airway pressure was similar among level ${ }_{100}$ and level $_{150}$ groups. Within all assistance levels (level ${ }_{50}$, level ${ }_{100}$, level $\left._{150}\right), \mathrm{P}_{\max }$ was higher with NAVA than with PAV and PSV $(P=0.001$; Figure 1 , Table 3$)$. At level ${ }_{50}$ and level ${ }_{100}$, $\mathrm{V}_{\mathrm{T}}$ was similar among modes. However, at a high assistance level, $V_{T}$ was significantly higher with PSV $_{150}$ than with NAVA $_{150}$ and PAV $_{150}(P<0.05)$. Tidal volume was similar with NAVA and PAV regardless of the assistance level. Inspiratory time and RR remained similar within all modes and at each level of assistance. Of note, at level ${ }_{100}$, and level $_{150}, \mathrm{EAdi}_{\max }$ and $\mathrm{EAdi}_{\mathrm{AUC}}$ were higher in PAV than in PSV (Figure 2; Table 3). Whereas the $\mathrm{V}_{\mathrm{T}} /$ EAdi $_{\max }$ ratio was similar among groups at $\operatorname{level}_{50}$, it was higher with PSV than with PAV at level ${ }_{100}$ and level ${ }_{150}$ $(P<0.0001)$. In addition, the $\mathrm{V}_{\mathrm{T}} /$ EAdi $_{\max }$ ratio was higher with PSV $(P<0.0001)$ but did not differ between PAV and NAVA regardless of the assistance level.

\section{Breath-by-breath variability}

Group median values for coefficient of variation $V_{T}$ and EAdi $_{\max }$ are provided in Figure 3 (see also Additional file 5). The coefficient of variation of $V_{T}$ was higher with PAV and NAVA than with PSV at level ${ }_{100}$ and level $_{150}(P<0.05)$, whereas the coefficient of variation of $\mathrm{V}_{\mathrm{T}}$ was similar between NAVA and PAV at each level of assistance. Conversely, the coefficient of variation of EAdi $_{\max }$ did not change according to ventilator mode and level of assistance, except at level ${ }_{150}$, where it was lower with $\mathrm{PAV}_{150}$ than with $\mathrm{PSV}_{150}$.

\section{Patient-ventilator interaction}

Table 4 and Additional file 6 show the inspiratory and expiratory trigger delays, the correlation between both 
Table 1 Patient characteristics at enrollment

\begin{tabular}{|c|c|c|c|c|c|c|c|}
\hline Patient no. & Age (years) & BMI (kg.m $\left.{ }^{-2}\right)$ & SAPS 2 & Admission diagnosis & $\begin{array}{l}\text { MV duration before } \\
\text { inclusion (days) }\end{array}$ & $\mathrm{FiO}_{2}$ & PEEP $\left(\mathrm{cmH}_{2} \mathrm{O}\right)$ \\
\hline 1 & 70 & 32.0 & 61 & Pneumonia & 8 & 0.5 & 4 \\
\hline 2 & 90 & 29.9 & 63 & ARDS & 2 & 0.4 & 5 \\
\hline 3 & 83 & 16.0 & 55 & ARDS & 6 & 0.5 & 4 \\
\hline 4 & 67 & 37.6 & 56 & Pneumonia & 12 & 0.5 & 5 \\
\hline 5 & 77 & 27.8 & 47 & $\begin{array}{l}\text { Acute respiratory failure due to } \\
\text { decompensation of COPD }\end{array}$ & 7 & 0.5 & 4 \\
\hline 6 & 60 & 27.5 & 35 & Pneumonia & 8 & 0.5 & 4 \\
\hline 7 & 60 & 25.0 & 26 & $\begin{array}{l}\text { Acute respiratory failure due to } \\
\text { decompensation of COPD }\end{array}$ & 7 & 0.5 & 4 \\
\hline 8 & 81 & 33.2 & 49 & Pneumonia & 4 & 0.4 & 4 \\
\hline 9 & 74 & 18.4 & 63 & Pneumonia & 6 & 0.5 & 4 \\
\hline 10 & 64 & 23.5 & 97 & Pneumonia & 11 & 0.5 & 5 \\
\hline 11 & 67 & 23.0 & 51 & ARDS & 12 & 0.5 & 4 \\
\hline 12 & 62 & 22.8 & 84 & ARDS & 7 & 0.5 & 4 \\
\hline 13 & 62 & 25.0 & 49 & Pneumonia & 2 & 0.5 & 5 \\
\hline 14 & 66 & 29.4 & 67 & $\begin{array}{l}\text { Acute respiratory failure due to } \\
\text { decompensation of COPD }\end{array}$ & 21 & 0.5 & 5 \\
\hline 15 & 65 & 26.0 & 72 & Pneumonia & 12 & 0.5 & 5 \\
\hline 16 & 67 & 31.6 & 46 & Pneumonia & 2 & 0.4 & 5 \\
\hline Median (IQR) & $67(63-75)$ & $27(23-30)$ & $55(48-64)$ & & $7.0(5.5-11.0)$ & $0.5(0.5-0.5)$ & $4(4-5)$ \\
\hline
\end{tabular}

M, male; F, female; BMI, body mass index; SAPS II, Simplified Acute Physiology Score II; MV, mechanical ventilation; PEEP, positive end-expiratory pressure; $I Q R$, interquartile range; ARDS, acute respiratory distress syndrome, COPD, chronic obstructive pulmonary disease.

$\mathrm{V}_{\mathrm{T}}$ and $\mathrm{P}_{\max }$ and EAdi, and the prevalence of patientventilator asynchrony in each condition. Inspiratory trigger delay was significantly lower in NAVA than in PAV and PSV at level $_{100}$ and level $_{150}$, respectively. Similarly, expiratory trigger delay was lower during NAVA $_{100}$ and NAVA ${ }_{150}$ than during PSV 100 and $\mathrm{PSV}_{150}$, respectively (Table 4 ). The correlation between EAdi $_{\mathrm{AUC}}$ and $\mathrm{V}_{\mathrm{T}}$, was higher during NAVA and PAV than during PSV (Table 4). The correlation between EAdi $_{\max }$ and $\mathrm{P}_{\max }$ was higher during NAVA than during PAV and PSV (Table 4). At each level of assistance, almost no ineffective efforts were reported with PAV and NAVA, whereas the ineffective efforts were detected with PSV at a higher level $(P<0.05)$. Inversely, although very few double-triggering events were observed with PSV and PAV, the prevalence of double triggering was significantly higher with NAVA $(P<0.05$, Table 4$)$. Type II double triggering was due to ventilator cycled off when the EAdi dropped to $70 \%$ of its peak, followed by a rebound in inspiratory flow, cause of the retriggering, when cycled off to PEEP (see Additional file 3).

Table 2 Assistance levels in each experimental condition

\begin{tabular}{|c|c|c|c|c|}
\hline Mode, assistance setting & Level $_{50}$ & Level $_{100}$ & Level $_{150}$ & Notes \\
\hline PSV, inspiratory pressure $\left(\mathrm{cmH}_{2} \mathrm{O}\right)$ & $7.0(7.0-7.2)$ & $14.0(11.5-15.2)$ & $21.0(17.2-21.7)$ & $\begin{array}{l}\text { The inspiratory pressure support level, set by the clinician, is } \\
\text { kept constant regardless of the mechanical properties of the } \\
\text { lung/thorax and patient effort. }\end{array}$ \\
\hline NAVA, NAVA level $\left(\mathrm{cmH}_{2} \mathrm{O} / \mu \mathrm{V}\right)$ & $0.6(0.4-0.9)$ & $1.3(0.8-1.8)$ & $1.9(1.2-2.7)$ & $\begin{array}{l}\text { The NAVA level is a proportional gain factor expressed in } \\
\mathrm{CmH}_{2} \mathrm{O} / \mu \mathrm{V} \text { of EAdi. It represents the magnitude (in } \mathrm{CmH}_{2} \mathrm{O} \text { ) } \\
\text { of positive airway pressure applied per } \mu \mathrm{V} \text { EAdi during the } \\
\text { course of each inspiration. }\end{array}$ \\
\hline PAV, proportion of assistance (\%) & $27(25-35)$ & $55(50-70)$ & $82(75-95)$ & $\begin{array}{l}\text { The proportion of assistance is the percentage of work } \\
\text { provided by the ventilator. The rest of the work is provided } \\
\text { by the patient. }\end{array}$ \\
\hline
\end{tabular}




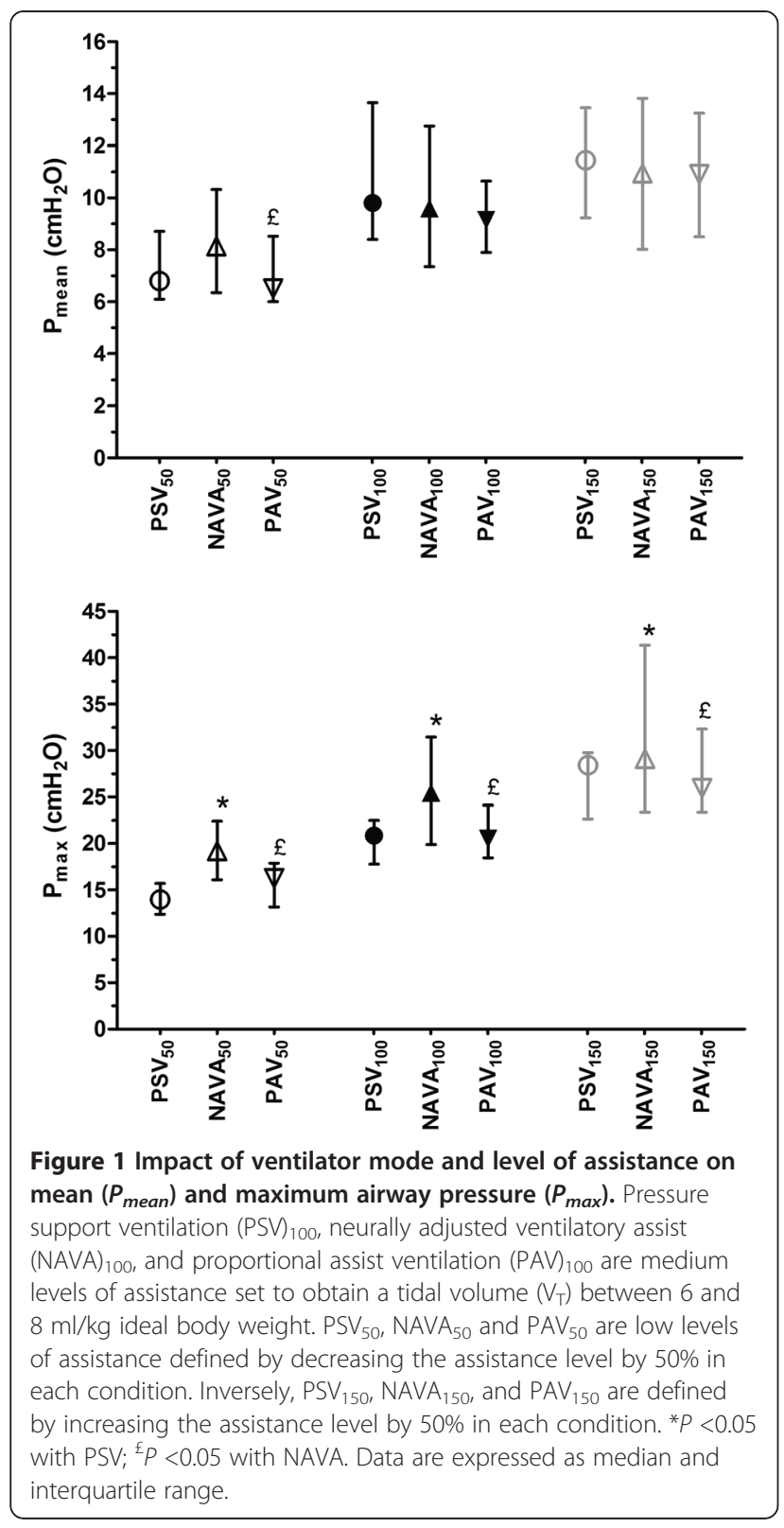

No autotriggering was observed in any condition. Overall, the asynchrony index was significantly lower with $\mathrm{PAV}_{50}$ and $\mathrm{PAV}_{100}$ than with NAVA 50 and NAVA 100 , respectively $(\mathrm{P}<0.05)$. Of note, only two patients exhibited an $\mathrm{AI}>10 \%$ in $\mathrm{PSV}_{150}$, mostly due to a high number of ineffective efforts (patients 7 and 14). Dyspnea was able to be evaluated in only two patients because of insufficient cooperation (data not shown).

\section{Gas exchange}

Neither the mode (PSV, NAVA, PAV) nor the level of assistance (level $\left.\mathrm{l}_{50}, 100,150\right)$ influenced $\mathrm{PaO}_{2}, \mathrm{PaCO}_{2}$, or $\mathrm{pH}$, which remained not significantly different between all conditions, except for $\mathrm{PaCO}_{2}$ that was higher and $\mathrm{pH}$ that was lower with $\mathrm{PAV}_{100}$, than with $\mathrm{NAVA}_{100}$ (see Additional file 7 for detailed blood gas values).

\section{Discussion}

The main findings of our study are as follows: (1) PAV and NAVA both prevented overassistance-induced hyperinflation, in contrast with PSV; (2) PAV and NAVA restored a comparable level of breathing-pattern variability that was greater than the variability observed with PSV; (3) Regardless of the level of assistance, PAV and NAVA induced less patient-ventilator asynchrony than PSV, with the exception of double triggering, which was more frequent with NAVA. The similarities observed between NAVA and PSV in terms of breathing pattern, variability, and asynchrony are consistent with the conceptual similarities of these two modes.

\section{Breathing pattern and central respiratory neural output}

Increasing PSV assist levels were associated with increasing $V_{T}$ values, in keeping with previous data $[29,30]$. In contrast, $\mathrm{V}_{\mathrm{T}}$ remained stable with NAVA and PAV, despite increasing assist levels [12,31], suggesting that these modes protect against overdistention. With PSV, the end of the patient's inspiratory effort does not determine cycling-off of the ventilator. A patient may therefore trigger a PSV breath with a small inspiratory effort, then relax, and be passively insufflated. If this breath is given at an excessive assist level, the insufflation may continue while the patient has already stopped inspiring. In contrast, with PSV, NAVA and PAV deliver an insufflation that stops when either the output of the inspiratory centers to the diaphragm ends, in the case of NAVA (12), or when the inspiratory muscle activity ends, in the case of PAV.

In addition, because overdistention contributes to downregulate the activity of respiratory control centers (29), tidal volume is maintained constant with PAV and NAVA but not with PSV. The robustness of this protective biofeedback provided by proportional modes, as opposed to PSV, is illustrated in the present study by the marked alteration of the coupling between $V_{T}$ and EAdi $_{\text {max }}$ (that is, higher $\mathrm{V}_{\mathrm{T}}$ /EAdi ratio) observed with PSV at high levels of assistance (see Figure 2), which was not observed with the two proportional modes.

\section{Breath-by-breath variability}

Fluctuations in the resting breathing pattern of healthy humans have been known for a long time [32]. Breathing pattern variability seems to originate from the activity of central pattern generators [33]. It is further influenced by the load-capacity relationship of the respiratory system: the higher the loading, the lower the variability $[19,34,35]$.

In the present study, the variability of $V_{T}$ with NAVA and PAV was greater than with PSV at each assistance 

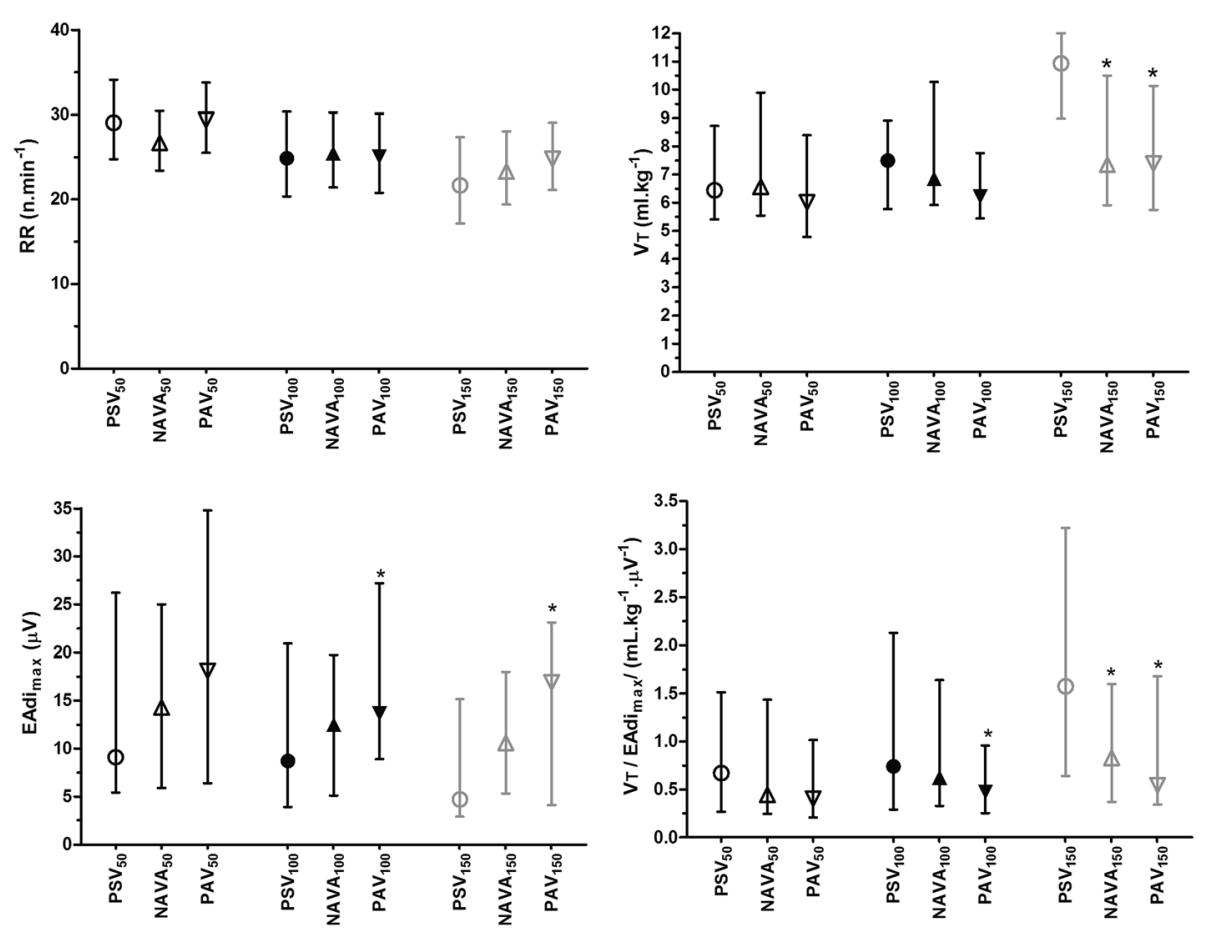

Figure 2 Impact of ventilator mode and level of assistance on the major descriptors of breathing pattern and diaphragmatic electrical activity (EAdi). Pressure support ventilation (PSV) 100 , neurally adjusted ventilatory assist (NAVA) 100 , and proportional assist ventilation (PAV) 100 are medium levels of assistance set to obtain a tidal volume $\left(V_{T}\right)$ between 6 and $8 \mathrm{ml} / \mathrm{kg}$ ideal body weight. PSV $V_{50}, N A V A_{50}$ and PAV 50 are low levels of assistance defined by decreasing the assistance level by $50 \%$ in each condition. Inversely, $\mathrm{PSV}_{150}, \mathrm{NAVA}_{150}$, and PAV 150 are defined by increasing the assistance level by $50 \%$ in each condition. EAdi ${ }_{\text {max }}$ peak of EAdi; $R R$, respiratory rate; $V_{T} /$ Eadi max $_{\text {, }}$ neuromechanical coupling. ${ }^{*} P<0.05$ with PSV. Data are expressed as median and interquartile range.

level. In contrast, the variability of EAdi was similar between the three modes, except at high assistance level. These data indicate that the increase in breath-to-breath variability observed during NAVA and PAV is actually due to "unmasking" of the underlying variability in central respiratory neural output and is a direct result of improvement of neuromechanical coupling. To our knowledge, these data, previously described in NAVA [19], have never been described with PAV. They suggest that PAV and NAVA both improve neuromechanical coupling in similar ways.

\section{Patient-ventilator interaction}

As previously observed, NAVA and PAV improved patient-ventilator synchrony as compared with PSV [12,21,22,24,25,31]. Although inspiratory trigger delays in all modes were consistently greater than previously reported [11,36,37], lower inspiratory and expiratory trigger delays seemed to be more frequently noted in NAVA. Wide variability of the delays (see Additional file 6) and their greater values can be ascribed to different ventilators used, varying levels of assist provided, experimental settings themselves, and the different etiologies of respiratory failure. It is noteworthy that, in the present study, PAV and NAVA provided a similar benefit on ineffective triggering. It suggests that PAV and NAVA improve the relationship between EAdi and tidal volume in a similar way, which in turn prevents chest hyperinflation, a major risk factor for ineffective triggering [7].

Two types of double triggering have been described in NAVA [25]. Type I double triggering is the result of a biphasic EAdi signal, but its significance is unknown, which is why, strictly speaking, it cannot be considered to be patient-ventilator asynchrony. With type II double triggering, however, one neural inspiration triggers two breaths, which was due to ventilator cycle off when the EAdi dropped to $70 \%$ of its peak, followed by a rebound in inspiratory flow, cause of the re/-triggering, when cycled off to PEEP. Pneumatic trigger set to pressure instead of flow might limit the rebound in inspiratory flow. We therefore considered only type II double triggering in the present study and observed that this asynchrony was significantly more frequent with NAVA than with PSV and PAV. The relevance of this asynchrony and how to decrease its prevalence in NAVA need further investigations [25].

The correlation between $V_{T}$ and $E_{A d i} i_{A U C}$ was much weaker in PSV than in NAVA or PAV, whereas no 
Table 3 Impact of ventilator mode and level of assistance on the main descriptors of breathing pattern and electrical activity of the diaphragm (EAdi)

\begin{tabular}{|c|c|c|c|}
\hline & PSV & NAVA & PAV \\
\hline \multicolumn{4}{|c|}{$P_{\text {mean }}\left(\mathrm{cmH}_{2} \mathrm{O}\right)$} \\
\hline level $_{50}$ & $6.8(6.1-8.7)$ & $8.1(6.3-10.3)$ & $6.5(6.0-8.5)^{£}$ \\
\hline level $_{100}$ & $9.8(8.4-13.6)$ & $9.6(7.3-12.7)$ & $9.1(7.9-10.6)$ \\
\hline level $_{150}$ & $11.4(9.2-13.4)$ & $10.9(8.0-13.8)$ & 10.9 (8.5-13.2) \\
\hline \multicolumn{4}{|c|}{$P_{\text {peak }}\left(\mathrm{cmH}_{2} \mathrm{O}\right)$} \\
\hline level $_{50}$ & $13.9(12.4-15.7)$ & $19.2(16.1-22.4)^{*}$ & $16.2(13.1-17.9)^{2}$ \\
\hline level $_{100}$ & $20.8(17.8-22.5)$ & $25.4(19.9-31.4)^{*}$ & $20.5(18.5-24.1)^{2}$ \\
\hline level $_{150}$ & $28.4(22.6-29.7)$ & $29.1(23.4-41.3)^{*}$ & $25.9(23.4-32.3)^{2}$ \\
\hline
\end{tabular}

Respiratory rate $\left(\mathrm{n} \cdot \mathrm{min}^{-1}\right.$ )

$$
\begin{aligned}
& \text { level }_{50} \\
& \text { level } \\
& \text { level }_{150}
\end{aligned}
$$

Tidal volume

(mL. $\left.\mathrm{kg}^{-1} \mathrm{IBW}\right)$

$$
\begin{aligned}
& \text { level }_{50} \\
& \text { level }_{100} \\
& \text { level }_{150}
\end{aligned}
$$

Minute ventilation $\left(\mathrm{mL} \cdot \mathrm{min}^{-1}\right)$

$$
\begin{aligned}
& \text { level }_{50} \\
& \text { level }_{100} \\
& \text { level }_{150}
\end{aligned}
$$$$
30(25-34)
$$$$
24(19-32)
$$

\begin{tabular}{|c|c|c|c|}
\hline level $_{50}$ & $0.72(0.67-0.82)$ & $0.77(0.60-0.84)$ & $0.73(0.61-0.99)$ \\
\hline level $_{100}$ & $0.72(0.67-0.95)$ & $0.78(0.61-0.93)$ & $0.76(0.64-1.06)$ \\
\hline level $_{150}$ & $0.85(0.69-1.18)$ & $0.79(0.59-0.93)$ & $0.83(0.64-1.09)$ \\
\hline \multicolumn{4}{|l|}{ EAdi $_{\max }$} \\
\hline level $_{50}$ & $9.1(5.4-26.2)$ & $14.3(5.9-25.0)$ & $18.1(6.4-34.8)$ \\
\hline level $_{100}$ & $8.7(3.9-20.9)$ & $12.5(5.1-19.7)$ & $13.7(8.9-27.2)^{*}$ \\
\hline level $_{150}$ & $4.7(2.9-15.1)$ & $10.6(5.3-18.0)$ & $10.9(4.1-13.1)^{*}$ \\
\hline \multicolumn{4}{|l|}{ EAdi $_{A \cup C}$} \\
\hline level $_{50}$ & $9.5(3.9-13.6)$ & $9.9(4.8-16.0)$ & $13.2(4.7-19.9)$ \\
\hline level $_{100}$ & $7.1(3.6-13.5)$ & $8.5(4.9-12.3)$ & $12.2(6.2-18.8)^{*}$ \\
\hline level $_{150}$ & $4.3(2.4-8.7)$ & $8.9(4.4-11.4)$ & $11.4(3.3-14.5)^{*}$ \\
\hline \multicolumn{4}{|l|}{$\mathrm{V}_{\mathrm{T}} / \mathrm{EAdi}_{\max }$} \\
\hline level $_{50}$ & $0.67(0.27-1.51)$ & $0.44(0.24-1.43)$ & $0.40(0.20-1.01)$ \\
\hline level $_{100}$ & $0.74(0.29-2.13)$ & $0.62(0.33-1.64)$ & $0.47(0.25-0.96)^{x}$ \\
\hline level ${ }_{150}$ & $1.67(0.64-3.22)$ & $0.83(0.37-1.60)^{*}$ & $0.54(0.34-1.68)^{*}$ \\
\hline
\end{tabular}$$
28(25-32)
$$$$
27(22-30)
$$$$
23(17-25)
$$$$
25(20-29)
$$

$30(26-34)$

$28(17-31)$

$26(18-30)$

Inspiratory time (sec)

EAdi $_{\text {max }}$, peak EAdi; EAdi $_{\text {Auc, }}$ area under the EAdi curve; $P_{\text {mean; }}$ mean inspiratory airway pressure; $P_{\max }$, maximum inspiratory airway pressure; $P S V$, pressure support ventilation; PAV, proportional assist ventilation; NAVA, neurally adjusted ventilatory assist.

Level ${ }_{100}$ is a medium assistance level set to obtain a VT of 6 to $8 \mathrm{ml} / \mathrm{kg}$ ideal body weight. Level ${ }_{50}$ is a low assistance level defined as level ${ }_{100}$ decreased by $50 \%$. Level ${ }_{150}$ is a high assistance level defined as level ${ }_{100}$ increased by $50 \%$. Data are provided as median (interquartile range). ${ }^{*} P<0.05$ with PSV; ${ }^{£} P<0.05$ with NAVA.
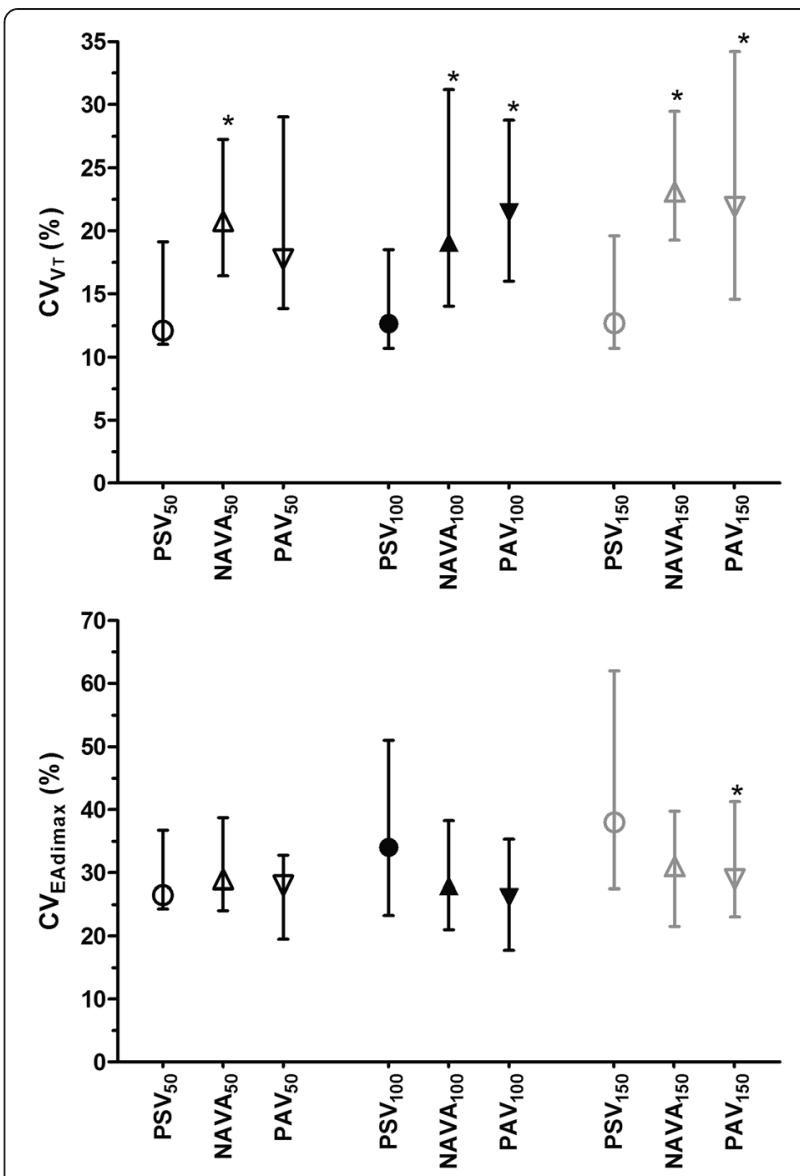

Figure 3 Impact of ventilator mode and level of assistance on the coefficient of variation of tidal volume $\left(\mathrm{CV}_{\mathrm{VT}}\right)$ and maximum electrical activity of the diaphragm $\left(\mathrm{CV}_{\text {EAdimax }}\right)$. Pressure support ventilation (PSV) 100 , neurally adjusted ventilatory assist (NAVA) ${ }_{100}$, and proportional assist ventilation (PAV) 100 are medium levels of assistance set to obtain a tidal volume $\left(\mathrm{V}_{T}\right)$ between 6 and $8 \mathrm{ml} / \mathrm{kg}$ ideal body weight. PSV $50, \mathrm{NAVA}_{50}$ and $\mathrm{PAV}_{50}$ are low levels of assistance defined by decreasing the assistance level by $50 \%$ in each condition. Inversely, $\mathrm{PSV}_{150}, \mathrm{NAVA}_{150}$ and $\mathrm{PAV}_{150}$ are defined by increasing the assistance level by $50 \%$ in each condition. ${ }^{*} P<0.05$ with PSV; ${ }^{£} P<0.05$ with NAVA; Data are expressed as median and interquartile range.

significant difference was found between NAVA and PAV, which demonstrates that these two modes provide an assistance that is proportional to the central respiratory drive. This is consistent with the recent report from Akoumianaki et al. [38], showing that the correlation between the inspiratory integral of transdiaphragmatic pressure and the $V_{T}$ was weaker with NAVA than with PAV [38]. Interestingly, the correlation between EAdi max $_{\max }$ and $\mathrm{P}_{\max }$ was higher in NAVA than in PAV, which may have two distinct explanations. First, during NAVA, EAdi and airway pressure are by definition strictly proportional and a strong correlation between EAdi max $_{\max }$ and $\mathrm{P}_{\max }$ is intrinsic to NAVA. Second, as opposed to NAVA 
Table 4 Impact of ventilator mode and level of assistance on patient-ventilator interaction and asynchrony indices

\begin{tabular}{|c|c|c|c|}
\hline & PSV & NAVA & PAV \\
\hline \multicolumn{4}{|c|}{$\begin{array}{l}\text { Inspiratory trigger } \\
\text { delay (msec) }\end{array}$} \\
\hline level $_{50}$ & $162(109-241)$ & $157(138-289)$ & $185(140-305)$ \\
\hline level $_{100}$ & $170(140-282)$ & $124(100-238)$ & $224(176-280)^{£}$ \\
\hline level $_{150}$ & $266(140-427)$ & $164(99-278)^{*}$ & $201(166-317)$ \\
\hline \multicolumn{4}{|c|}{$\begin{array}{l}\text { Expiratory trigger } \\
\text { delay (msec) }\end{array}$} \\
\hline level $_{50}$ & $156(112-191)$ & $151(125-175)$ & $152(107-175)$ \\
\hline level $_{100}$ & $212(176-273)$ & $157(140-188)^{*}$ & $182(116-230)$ \\
\hline level $_{150}$ & $255(227-541)$ & $146(131-218)^{*}$ & $225(169-333)$ \\
\hline \multicolumn{4}{|c|}{$\begin{array}{l}\text { Relationship between } \\
P_{\max } \text { and EAdi } \max _{\max }\left(r^{2}\right)\end{array}$} \\
\hline level $_{50}$ & $0.02(0.01-0.04)$ & $0.56(0.51-0.65)^{*}$ & $0.02(0.00-0.04)^{ \pm}$ \\
\hline level $_{100}$ & $0.03(0.01-0.08)$ & $0.85(0.78-0.90)^{*}$ & $0.04(0.00-0.07)^{£}$ \\
\hline level $_{150}$ & $0.03(0.01-0.06)$ & $0.64(0.43-0.88)^{*}$ & $0.03(0.02-0.08)^{£}$ \\
\hline \multicolumn{4}{|c|}{$\begin{array}{l}\text { Relationship between } V_{T} \\
\text { and } E_{A d i}\left(r_{A \cup C}\left(r^{2}\right)\right.\end{array}$} \\
\hline level $_{50}$ & $0.15(0.14-0.19)$ & $0.48(0.40-0.57)^{*}$ & $0.39(0.25-0.45)^{*}$ \\
\hline level $_{100}$ & $0.13(0.06-0.22)$ & $0.64(0.60-0.79)^{*}$ & $0.29(0.21-0.42)$ \\
\hline level $_{150}$ & $0.02(0.01-0.06)$ & $0.72(0.65-0.88)^{*}$ & $0.28(0.25-0.41)^{*}$ \\
\hline \multicolumn{4}{|c|}{ Ineffective efforts $\left(n \cdot \min ^{-1}\right.$ ) } \\
\hline level $_{50}$ & $0.00(0.00-0.07)$ & $0.00(0.00-0.00)^{*}$ & $0.00(0.00-0.00)^{*}$ \\
\hline level $_{100}$ & $0.03(0.00-0.26)$ & $0.00(0.00-0.00)^{*}$ & $0.00(0.00-0.00)^{*}$ \\
\hline level $_{150}$ & $0.27(0.01-1.23)$ & $0.00(0.00-0.00)^{*}$ & $0.00(0.00-0.00)^{*}$ \\
\hline \multicolumn{4}{|c|}{ Auto-triggering $\left(\mathrm{n} \cdot \mathrm{min}^{-1}\right)$} \\
\hline level $_{50}$ & $0.00(0.00-0.03)$ & $0.00(0.00-0.00)$ & $0.00(0.00-0.00)$ \\
\hline level $_{100}$ & $0.00(0.00-0.03)$ & $0.00(0.00-0.00)$ & $0.00(0.00-0.00)$ \\
\hline level $_{150}$ & $0.00(0.00-0.00)$ & $0.00(0.00-0.00)$ & $0.00(0.00-0.00)$ \\
\hline \multicolumn{4}{|c|}{ Double triggering $\left(\mathrm{n} \cdot \mathrm{min}^{-1}\right)$} \\
\hline level $_{50}$ & $0.00(0.00-0.00)$ & $0.42(0.08-0.50)^{*}$ & $0.00(0.00-0.00)^{£}$ \\
\hline level $_{100}$ & $0.00(0.00-0.18)$ & $0.33(0.10-0.92)^{*}$ & $0.00(0.00-0.10)^{£}$ \\
\hline level $_{150}$ & $0.00(0.00-0.21)$ & $0.30(0.02-0.87)^{*}$ & $0.00(0.00-0.20)^{£}$ \\
\hline \multicolumn{4}{|c|}{ Asynchrony index (\%) } \\
\hline level $_{50}$ & $0.21(0.00-0.65)$ & $1.41(0.34-2.91)^{*}$ & $0.13(0.00-0.44)^{£}$ \\
\hline level $_{100}$ & $0.61(0.04-1.28)$ & $1.73(0.38-2.69)$ & $0.00(0.00-0.58)^{£}$ \\
\hline level $_{150}$ & $1.65(0.58-5.77)$ & $1.17(0.05-3.99)$ & $0.19(0.00-1.12)$ \\
\hline
\end{tabular}

EAdi $_{\text {Auc }}$ area under the diaphragmatic electrical activity curve; PSV, pressure support ventilation; NAVA, neurally adjusted ventilatory assist; PAV, proportional assist ventilation; VT, tidal volume. Level ${ }_{100}$ is a medium assistance level set to obtain a VT of 6 to $8 \mathrm{ml} / \mathrm{kg}$ ideal body weight. Level ${ }_{50}$ is a low assistance level defined as level ${ }_{100}$ decreased by $50 \%$. Level ${ }_{150}$ is a high assistance level defined as level $_{100}$ increased by $50 \%$.

The number of each type of asynchrony is reported as the total number of each event per minute. Asynchrony index is defined as the total number of asynchrony events $\times 100 /$ (ventilator respiratory rate + ineffective efforts).

${ }^{*} P<0.05$ with PSV; ${ }^{\mp} P<0.05$ with NAVA; data are expressed as median (interquartile range).

that delivers an assistance proportional to the only diaphragm activity, PAV delivers an assistance that is proportional to the whole inspiratory activity of respiratory muscles. As a consequence, PAV integrates not only diaphragm activity, but also the activity of extradiaphragmatic inspiratory muscles such as scalenes or parasternal intercostal muscles [39].

\section{Limitations of the study}

Our study has several limitations. First, as patients at high risk of asynchrony (for example, difficult-to-wean or severe COPD patients) were not specifically selected in this study [7] and because we targeted a $V_{T}$ of 6 to $8 \mathrm{ml} / \mathrm{kg}$ in level ${ }_{100}$ [40], a very low incidence of asynchrony was observed with all modes and conditions. This study may therefore have underestimated the benefits of NAVA and PAV [20,39,41,42], but we deliberately decided to compare these modes in patients in the recovery phase after acute respiratory failure encountered in daily practice rather than in a very selected population, with the risk of showing results that would be transposable only to a niche population.

Second, the trials in our study were probably not sufficiently long to allow an improvement of gas exchange. This might explain why, despite a greater variability of the breathing pattern in PAV and NAVA, no impact on $\mathrm{PaO}_{2}$ was observed in contrast with previously published results [14].

Third, the choice of a resulting $\mathrm{V}_{\mathrm{T}}$ of 6 to $8 \mathrm{ml} / \mathrm{kg}$ to match the assistance level ${ }_{100}$ with the three modes may be questionable. Indeed, a poor correlation between $V_{T}$ and PAV \%Assist [43] as well as NAVA level [18] has been reported. In addition, the high $\mathrm{V}_{\mathrm{T}}$ variability may have jeopardized the accuracy of its setting. However, the fact that we observed a comparable $\mathrm{P}_{\text {mean }}$ with the three modes at assistance level ${ }_{100}$ suggests that the patients received a comparable level of assistance.

Fourth, because we focused on patients in the recovery phase after acute respiratory failure and because PSV $_{50}$ could not be lower than $7 \mathrm{cmH}_{2} \mathrm{O}, \mathrm{PSV}_{100}$ settings could sometimes be very close to $\mathrm{PSV}_{50}$.

Fifth, although the expiration starts at $70 \%$ of the EAdi $_{\text {max }}$ in NAVA, the expiratory trigger delay was calculated as the time difference between EAdi ${ }_{\max }$ and the end of insufflation by the ventilator within the three modes. Finally, contrary to the sequence of the ventilatory modes tested, the sequence of the level of assistance was not randomized. Therefore, we cannot rule out a potential time effect.

\section{Clinical implications}

Most of our findings are potentially clinically relevant. Lung-protective ventilation has become a major concern in ICU patients, even in those without acute respiratory distress syndrome [44,45]. Preventing alveolar overdistention and subsequent volotrauma caused by lung hyperinflation is now a major therapeutic goal. In this 
respect, NAVA and PAV provide an interesting tool to prevent overassistance-induced hyperinflation.

Variability of breathing pattern has become a matter of concern in ICU patients, as a recent study showed that a higher variability of respiratory rate was associated with better prognosis [46]. In addition, a more variable breathing pattern is associated with better pulmonary function in animal models of lung injury [47-51]. Finally, severe patient-ventilator asynchrony is associated with longer duration of mechanical ventilation and a greater need for tracheostomy [7]. Of note, patient-ventilator asynchrony may be either a cause or a consequence of the severity of the respiratory disease requiring mechanical ventilation. Whether optimization of ventilatory settings, by using PAV or NAVA, can shorten the duration of mechanical ventilation by reducing the incidence of asynchrony, has therefore not been demonstrated.

\section{Conclusion}

In conclusion, PAV and NAVA both prevent overdistention and improve neuromechanical coupling and patient-ventilator asynchrony in fairly similar ways compared with PSV. Further studies are needed to evaluate the possible clinical benefits of NAVA and PAV on clinical outcomes, especially in the recovery phase of acute respiratory failure.

\section{Key messages}

- The variability of $\mathrm{V}_{T}$ with NAVA and PAV is greater than with PSV at each assistance level.

- PAV and NAVA both restore "natural" variability of breathing.

- The increase in breath-to-breath variability observed during NAVA and PAV is due to "unmasking" of the underlying variability in central respiratory neural output and is a direct result of improvement of neuromechanical coupling.

- NAVA and PAV both improve patient-ventilator synchrony as compared with PSV, especially on ineffective triggering.

\section{Additional files}

Additional file 1: Waveforms of EAdi, pressure and flow for all three modes ( PSV $_{100}, \mathrm{NAVA}_{100}, \mathrm{PAV}_{100}$ ) in the same patient.

Additional file 2: Definitions of patient- ventilator interaction indices and the main asynchronies collected.

Additional file 3: Example of Type II double triggering under NAVA. Additional file 4: Inspiratory pressure $\left(\mathrm{cmH}_{2} \mathrm{O}\right)$ over PEEP for each patient under the three modes and three assist levels.
Additional file 5: Impact of ventilator mode and assistance level on the coefficients of variation of neural respiratory rate, tidal volume, and peak electrical activity of the diaphragm (EAdi ${ }_{\text {max }}$ ).

Additional file 6: Distribution of the inspiratory trigger delays per mode.

Additional file 7: Impact of ventilator mode and level of assistance on gas exchange.

\section{Abbreviations}

Al: Asynchrony index; CV: coefficient of variation; $\mathrm{CV}_{\text {EAdimax: coefficient }}$ of variation of EAdi $i_{\text {maxi }}$ EAdi: electrical activity of the diaphragm; EAdi max: $_{\text {maximum electrical activity of the diaphragm; EAdi }}$ Auc: integrated EAdi activity; IQR: interquartile range; NAVA: neurally adjusted ventilatory assist; PAV: proportional assisted ventilation; PEEP: positive end-expiratory pressure; $P_{\text {max }}$ : peak airway pressure; PSV: pressure support ventilation; RR: respiratory rate; Ti: inspiratory time; VT: tidal volume.

\section{Competing interests}

The Association pour le Développement et l'Organisation de la Recherche en Pneumologie, a nonprofit structure that supports the research activities of the "Service de Pneumologie et Réanimation Médicale, Groupe Hospitalier Pitié-Salpêtrière," has received an unrestricted research grant from Maquet France SA, Orléans, France (2009), and Covidien, Dublin, Ireland (2013), to support pathophysiological research studies on NAVA and PAV, respectively. A. Demoule is the principal investigator of a study on NAVA, has been a consultant for Covidien, and has given lectures for Covidien and Maquet. The others authors have no conflict of interest.

\section{Authors' contributions}

MS conceived the study and contributed to the data collection, analysis, statistics, and writing of the manuscript. FK contributed to the data collection and analysis. JC contributed to data collection and analysis. TP contributed to the data analysis and the revision of the manuscript. EM contributed to the data collection, their analysis, and the revision of the manuscript. RP contributed to the data collection and revised the manuscript. TS drafted the design of the study, and contributed to the writing and the revision of the manuscript. AD conceived the study and contributed to the data collection, analysis, statistics, and writing of the manuscript. All authors read and approved the manuscript.

\section{Authors' information}

Dr Matthieu Schmidt is an ICU physician.

Dr Felix Kindler is an ICU physician.

Dr Jérôme Cecchini is an ICU physician.

Dr Elise Morawiec is an ICU physician.

Dr Romain Persichini is an ICU physician.

Pr Thomas Similowski is a Professor of Pulmonology. He is the chair of the Department of Pulmonology and Medical ICU in La Pitie Salpetriere hospital in Paris.

Pr Alexandre Demoule is a Professor of intensive care.

\section{Acknowledgements}

Matthieu Schmidt was supported by the French Intensive Care Society (SRLF); the "Fonds de dotation Recherche en Santé Respiratoire 2012" the "Collège des Enseignants de Réanimation Médicale" and the "Fonds d'Etudes et de Recherche du Corps Médical-Assistance Publique des Hôpitaux de Paris". Written informed consent was obtained from the patients for publication of their individual details and accompanying images in this manuscript. The consent form is held by the authors and is available for review by the Editor-in-Chief.

\section{Author details}

'Sorbonne Universités, UPMC Univ Paris 06, UMR_S 1158 Neurophysiologie Respiratoire Expérimentale et Clinique, F-75005 Paris, France. ${ }^{2}$ INSERM, UMR_S 1158 Neurophysiologie Respiratoire Expérimentale et Clinique, F-75005 Paris, France. ${ }^{3}$ AP-HP, Groupe Hospitalier Pitié-Salpêtrière Charles Foix, Service de Pneumologie et Réanimation Médicale (Département R3S), F-75013 Paris, France. ${ }^{4}$ Université Pierre et Marie Curie-CNRS-INSERM, ICM, Equipe Neurologie et Thérapeutique Expérimentale, Hôpital de la Salpêtrière, Paris, France. ${ }^{5}$ U974, Institut National de la Santé et de la Recherche 
médicale, Paris, France. ${ }^{6}$ Service de Pneumologie et Réanimation Médicale, Groupe Hospitalier Pitié-Salpêtrière, 47-83 boulevard de l'Hôpital, 75651 Paris, Cedex 13, France.

\section{Received: 6 June 2014 Accepted: 22 January 2015} Published online: 25 February 2015

\section{References}

1. Futier E, Constantin JM, Combaret L, Mosoni L, Roszyk L, Sapin V, et al. Pressure support ventilation attenuates ventilator-induced protein modifications in the diaphragm. Crit Care. 2008;12:R116.

2. Hudson MB, Smuder AJ, Nelson WB, Bruells CS, Levine S, Powers SK. Both high level pressure support ventilation and controlled mechanical ventilation induce diaphragm dysfunction and atrophy. Crit Care Med. 2012:40:1254-60.

3. Levine S, Nguyen T, Taylor N, Friscia ME, Budak MT, Rothenberg P, et al. Rapid disuse atrophy of diaphragm fibers in mechanically ventilated humans. N Engl J Med. 2008;358:1327-35.

4. Esteban A, Frutos-Vivar F, Muriel A, Ferguson ND, Penuelas O, Abraira V, et al. Evolution of mortality over time in patients receiving mechanical ventilation. Am J Respir Crit Care Med. 2013;188:220-30.

5. Schmidt M, Banzett RB, Raux M, Morelot-Panzini C, Dangers L, Similowski T, et al. Unrecognized suffering in the ICU: addressing dyspnea in mechanically ventilated patients. Intensive Care Med. 2014;40:1-10.

6. Dreyfuss D, Soler P, Basset G, Saumon G. High inflation pressure pulmonary edema: respective effects of high airway pressure, high tidal volume, and positive end-expiratory pressure. Am Rev Respir Dis. 1988;137:1159-64.

7. Thille AW, Rodriguez P, Cabello B, Lellouche F, Brochard L. Patient-ventilator asynchrony during assisted mechanical ventilation. Intensive Care Med. 2006:32:1515-22

8. Sinderby C, Navalesi P, Beck J, Skrobik Y, Comtois N, Friberg S, et al. Neural control of mechanical ventilation in respiratory failure. Nat Med. 1999:5:1433-6.

9. Younes M. Proportional assist ventilation, a new approach to ventilatory support. Theory Am Rev Respir Dis. 1992;145:114-20.

10. Brander L, Leong-Poi H, Beck J, Brunet F, Hutchison SJ, Slutsky AS, et al. Titration and implementation of neurally adjusted ventilatory assist in critically ill patients. Chest. 2009;135:695-703.

11. Colombo D, Cammarota G, Bergamaschi V, De Lucia M, Corte FD, Navalesi P. Physiologic response to varying levels of pressure support and neurally adjusted ventilatory assist in patients with acute respiratory failure. Intensive Care Med. 2008:34:2010-8

12. Giannouli E, Webster K, Roberts D, Younes M. Response of ventilatordependent patients to different levels of pressure support and proportional assist. Am J Respir Crit Care Med. 1999:159:1716-25.

13. Brander L, Sinderby C, Lecomte F, Leong-Poi H, Bell D, Beck J, et al. Neurally adjusted ventilatory assist decreases ventilator-induced lung injury and non-pulmonary organ dysfunction in rabbits with acute lung injury. Intensive Care Med. 2009;35:1979-89.

14. Coisel Y, Chanques G, Jung B, Constantin JM, Capdevila X, Matecki S, et al. Neurally adjusted ventilatory assist in critically ill postoperative patients: a crossover randomized study. Anesthesiology. 2010;113:925-35.

15. Fernandez-Vivas M, Caturla-Such J, Gonzalez dela Rosa J, Acosta-Escribano J, Alvarez-Sanchez B, Canovas-Robles J. Noninvasive pressure support versus proportional assist ventilation in acute respiratory failure. Intensive Care Med. 2003:29:1126-33.

16. Gay PC, Hess DR, Hill NS. Noninvasive proportional assist ventilation for acute respiratory insufficiency: comparison with pressure support ventilation. Am J Respir Crit Care Med. 2001;164:1606-11.

17. Hernandez P, Maltais F, Gursahaney A, Leblanc P, Gottfried SB. Proportional assist ventilation may improve exercise performance in severe chronic obstructive pulmonary disease. J Cardiopulm Rehabil. 2001;21:135-42

18. Patroniti N, Bellani G, Saccavino E, Zanella A, Grasselli G, Isgro S, et al. Respiratory pattern during neurally adjusted ventilatory assist in acute respiratory failure patients. Intensive Care Med. 2012;38:230-9.

19. Schmidt M, Demoule A, Cracco C, Gharbi A, Fiamma MN, Straus C, et al. Neurally adjusted ventilatory assist increases respiratory variability and complexity in acute respiratory failure. Anesthesiology. 2010;112:670-81.
20. Wrigge H, Golisch W, Zinserling J, Sydow M, Almeling G, Burchardi H. Proportional assist versus pressure support ventilation: effects on breathing pattern and respiratory work of patients with chronic obstructive pulmonary disease. Intensive Care Med. 1999:25:790-8.

21. Appendini L, Purro A, Gudjonsdottir M, Baderna P, Patessio A, Zanaboni S, et al. Physiologic response of ventilator-dependent patients with chronic obstructive pulmonary disease to proportional assist ventilation and continuous positive airway pressure. Am J Respir Crit Care Med. 1999;159:1510-7.

22. Passam F, Hoing S, Prinianakis G, Siafakas N, Milic-Emili J, Georgopoulos D. Effect of different levels of pressure support and proportional assist ventilation on breathing pattern, work of breathing and gas exchange in mechanically ventilated hypercapnic COPD patients with acute respiratory failure. Respiration. 2003;70:355-61.

23. Schmidt M, Dres M, Raux M, Deslandes-Boutmy E, Kindler F, Mayaux J, et al. Neurally adjusted ventilatory assist improves patient-ventilator interaction during postextubation prophylactic noninvasive ventilation. Crit Care Med. 2012:40:1738-44

24. Xirouchaki N, Kondili E, Vaporidi K, Xirouchakis G, Klimathianaki M, Gavriilidis G, et al. Proportional assist ventilation with load-adjustable gain factors in critically ill patients: comparison with pressure support. Intensive Care Med. 2008;34:2026-34

25. Piquilloud L, Vignaux L, Bialais E, Roeseler J, Sottiaux T, Laterre PF, et al. Neurally adjusted ventilatory assist improves patient-ventilator interaction. Intensive Care Med. 2011;37:263-71.

26. Spahija J, de Marchie M, Albert M, Bellemare P, Delisle S, Beck J, et al. Patient-ventilator interaction during pressure support ventilation and neurally adjusted ventilatory assist. Crit Care Med. 2010;38:518-26.

27. Sinderby $C$, Beck J. Proportional assist ventilation and neurally adjusted ventilatory assist-better approaches to patient ventilator synchrony? Clin Chest Med. 2008;29:329-42. vii.

28. Barwing J, Ambold M, Linden N, Quintel M, Moerer O. Evaluation of the catheter positioning for neurally adjusted ventilatory assist. Intensive Care Med. 2009;35:1809-14

29. Leung P, Jubran A, Tobin MJ. Comparison of assisted ventilator modes on triggering, patient effort, and dyspnea. Am J Respir Crit Care Med. 1997:155:1940-8

30. Nava S, Bruschi C, Rubini F, Palo A, lotti G, Braschi A. Respiratory response and inspiratory effort during pressure support ventilation in COPD patients. Intensive Care Med. 1995;21:871-9.

31. Terzi N, Pelieu I, Guittet L, Ramakers M, Seguin A, Daubin C, et al. Neurally adjusted ventilatory assist in patients recovering spontaneous breathing after acute respiratory distress syndrome: physiological evaluation. Crit Care Med. 2010;38:1830-7.

32. Priban IP. An analysis of some short-term patterns of breathing in man at rest. J Physiol. 1963;166:425-34.

33. Fiamma MN, Straus C, Thibault S, Wysocki M, Baconnier P, Similowski T. Effects of hypercapnia and hypocapnia on ventilatory variability and the chaotic dynamics of ventilatory flow in humans. Am J Physiol Regul Integr Comp Physiol. 2007;292:R1985-93.

34. Anzueto A, Jubran A, Ohar JA, Piquette CA, Rennard SI, Colice G, et al. Effects of aerosolized surfactant in patients with stable chronic bronchitis: a prospective randomized controlled trial. JAMA. 1997;278:1426-31.

35. Jubran A, Parthasarathy S. Hypercapnic respiratory failure during weaning: neuromuscular capacity versus muscle loads. Respir Care Clin N Am. 2000:6:385-405. v.

36. Beck J, Gottfried SB, Navalesi P, Skrobik Y, Comtois N, Rossini M, et al. Electrical activity of the diaphragm during pressure support ventilation in acute respiratory failure. Am J Respir Crit Care Med. 2001;164:419-24.

37. Goulet R, Hess D, Kacmarek RM. Pressure vs flow triggering during pressure support ventilation. Chest. 1997:111:1649-53.

38. Akoumianaki E, Prinianakis G, Kondili E, Malliotakis P, Georgopoulos D. Physiologic comparison of neurally adjusted ventilator assist, proportional assist and pressure support ventilation in critically ill patients. Respir Physiol Neurobiol. 2014;203:82-9.

39. Kondili E, Prinianakis G, Alexopoulou C, Vakouti E, Klimathianaki M, Georgopoulos D. Respiratory load compensation during mechanical ventilation-proportional assist ventilation with load-adjustable gain factors versus pressure support. Intensive Care Med. 2006;32:692-9.

40. Thille AW, Cabello B, Galia F, Lyazidi A, Brochard L. Reduction of patientventilator asynchrony by reducing tidal volume during pressure-support ventilation. Intensive Care Med. 2008:34:1477-86. 
41. Peluso G, Marchese M, Furgi A, Ranieri M, Russo Spena S, Ravagnan G, et al. SV-IV, a major protein secreted from rat seminal vesicle epithelium, promotes lymphocyte cytotoxic activity against the lymphoblastoid Raji cell line in human peripheral blood mononuclear cells. Int J Cancer. 1997;72:321-8.

42. Krasniqi A, Limani D, Gashi-Luci L, Spahija G, Dreshaj IA. Primary hydatid cyst of the gallbladder: a case report. J Med Case Reports. 2010;4:29.

43. Marantz S, Patrick W, Webster K, Roberts D, Oppenheimer L, Younes M. Response of ventilator-dependent patients to different levels of proportional assist. J Appl Physiol (1985). 1996;80:397-403.

44. Lellouche F, Dionne S, Simard S, Bussieres J, Dagenais F. High tidal volumes in mechanically ventilated patients increase organ dysfunction after cardiac surgery. Anesthesiology. 2012;116:1072-82.

45. Serpa Neto A, Cardoso SO, Manetta JA, Pereira VG, Esposito DC, Pasqualucci Mde $\mathrm{O}$, et al. Association between use of lung-protective ventilation with lower tidal volumes and clinical outcomes among patients without acute respiratory distress syndrome: a meta-analysis. JAMA. 2012;308:1651-9.

46. Gutierrez G, Das A, Ballarino G, Beyzaei-Arani A, Turkan H, Wulf-Gutierrez M, et al. Decreased respiratory rate variability during mechanical ventilation is associated with increased mortality. Intensive Care Med. 2013;39:1359-67.

47. Arold SP, Mora R, Lutchen KR, Ingenito EP, Suki B. Variable tidal volume ventilation improves lung mechanics and gas exchange in a rodent model of acute lung injury. Am J Respir Crit Care Med. 2002;165:366-71.

48. Abreu M, Spieth PM, Pelosi P, Carvalho AR, Walter C, Schreiber-Ferstl A, et al. Noisy pressure support ventilation: a pilot study on a new assisted ventilation mode in experimental lung injury. Crit Care Med. 2008:36:818-27.

49. Beda A, Spieth PM, Handzsuj T, Pelosi P, Carvalho NC, Koch E, et al. A novel adaptive control system for noisy pressure-controlled ventilation: a numerical simulation and bench test study. Intensive Care Med. 2010;36:164-8.

50. Spieth PM, Guldner A, Beda A, Carvalho N, Nowack T, Krause A, et al. Comparative effects of proportional assist and variable pressure support ventilation on lung function and damage in experimental lung injury. Crit Care Med. 2012:40:2654-61.

51. Suki B, Alencar AM, Sujeer MK, Lutchen KR, Collins JJ, Andrade Jr JS, et al. Life-support system benefits from noise. Nature. 1998;393:127-8.

\section{Submit your next manuscript to BioMed Central and take full advantage of:}

- Convenient online submission

- Thorough peer review

- No space constraints or color figure charges

- Immediate publication on acceptance

- Inclusion in PubMed, CAS, Scopus and Google Scholar

- Research which is freely available for redistribution 